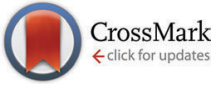

Cite this: Chem. Commun., 2015, 51, 7027

Received 18th February 2015, Accepted 19th March 2015

DOI: $10.1039 / \mathrm{c5cc01519g}$

www.rsc.org/chemcomm

\section{Oxidation with air by ascorbate-driven quinone redox cycling $\dagger+$}

\author{
Gastón Silveira-Dorta, ${ }^{a}$ Diego M. Monzón, ${ }^{a}$ Fernando P. Crisóstomo, ${ }^{a}$ \\ Tomás Martín, ${ }^{b}$ Víctor S. Martín ${ }^{a}$ and Romen Carrillo*a
}

\begin{abstract}
Transition metal-free oxidation with air at room temperature has been achieved by simply using ascorbate (vitamin C) and catalytic amounts of menadione (vitamin $\mathrm{K}_{3}$ ). A combination of the mentioned vitamins transforms atmospheric oxygen into hydrogen peroxide, which is able to oxidize arylboronic acids and other chemical moieties.
\end{abstract}

Oxidation is one of the most fundamental processes in chemistry. Conventional chemical oxidants, however, are usually toxic and there is an increasing academic and societal demand for environment-friendly oxidation methods. ${ }^{1}$ In this regard, molecular oxygen seems to be an ideal oxidant and an oxygen-atom source for organic synthesis: it is abundant, environmentally benign and inexpensive, particularly if used directly from air. ${ }^{2}$ However, the direct reaction of triplet dioxygen with singlet organic molecules is a spin-forbidden process. ${ }^{3}$ As a consequence, oxidation with atmospheric oxygen displays an extremely slow kinetics and it is usually accomplished only under transition metal catalysis, ${ }^{4}$ and/or very high temperatures. Transitionmetal-mediated reactions have raised several environmental and economic concerns, ${ }^{5}$ which have motivated the development of plenty of transition-metal-free synthetic methods. However only some examples of transition metal-free oxidation by air has been previously reported ${ }^{6}$ and in some cases the reagents employed are toxic and/or too expensive.

With the aim of developing an efficient, economic and green way to activate oxygen from air, we took inspiration from biological systems. The biological activation of triplet dioxygen for controlled chemical synthesis occurs via electron transport chains by redox reactions. Particularly promising for our purposes is the redox

\footnotetext{
${ }^{a}$ Departamento de Química Orgánica, Instituto Universitario de Bio-Orgánica “Antonio González” (IUBO), Centro de Investigaciones Biomédicas de Canarias (CIBICAN), Universidad de La Laguna, Avda. Astrofísico Fco. Sánchez 2, Apdo. Correos 456, 38200 - La Laguna, S/C. de Tenerife, Spain.E-mail: rocarril@ull.es ${ }^{b}$ Instituto de Productos Naturales y Agrobiología, CSIC Avda, Astrofísico Fco. Sánchez, 3, 38206 La Laguna, S/C. de Tenerife, Spain

$\dagger$ Dedicated in memoriam of Prof. Tsutomu Katsuki.

\$ Electronic supplementary information (ESI) available: Full experimental details, spectroscopic data and copies of NMR spectra. See DOI: 10.1039/c5cc01519g
}

performance of quinones. ${ }^{7}$ In fact, several quinone-type natural molecules are efficient electron carriers, which are able to transfer one electron to dioxygen by the so-called quinone redox cycling (Scheme 1a): one-electron reduction of the quinone by a suitable reducing agent generates a semiquinone, which transfers one electron to dioxygen and reconverts itself into the original quinone. ${ }^{8}$ Unfortunately, the single electron reduction of quinones is usually performed by reductases. A very appealing candidate as a reducing agent to mimic the enzymatic quinone redox cycling is ascorbate.

Indeed, vitamin $\mathrm{C}$ is a mild, inexpensive and non-toxic reducing agent which has been relatively underused in organic synthesis. ${ }^{9}$ In this regard, it is known that ascorbate can

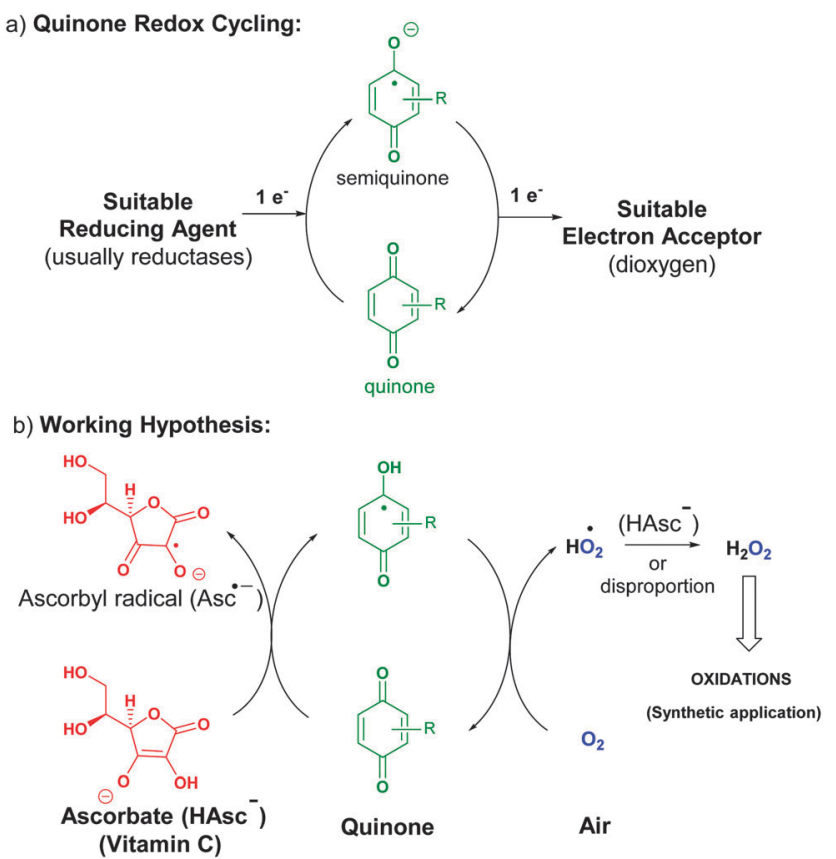

Scheme 1 (a) General quinone redox cycling. (b) Suggested activation of oxygen by ascorbate-driven quinone redox cycling through tandem proton-coupled electron transfer (PCET). 
promote quinone redox cycling. ${ }^{10}$ Furthermore, it has been reported that a combination of ascorbate and menadione (2-methyl-1,4naphthoquinone, also called vitamin $\mathrm{K}_{3}$ ) generates reactive oxygen species such as hydrogen peroxide in biological tissues. ${ }^{11}$ It seems, therefore, to be a very interesting starting point to develop a transition metal-free oxidation method with air (Scheme 1b). Herein we have combined the pro-oxidant activity of ascorbate (vitamin C), ${ }^{12}$ and the quinone redox cycling to develop an efficient and environment friendly method for oxidation by generating $\mathrm{H}_{2} \mathrm{O}_{2}$ from air at room temperature.

Oxidative hydroxylation of arylboronic acids to phenols was chosen as an optimal example to test the effective generation of hydrogen peroxide from air. Additionally, mild, economical and green synthesis of phenols, particularly by using air, is increasingly attracting attention. ${ }^{13}$ Oxidation of phenylboronic acid (1a) to phenol (2a) was evaluated in acetonitrile and $\mathrm{NaHCO}_{3}$ solution (1 M) stirring at room temperature in air, and protected from light to rule out any effect of irradiation. Several quinones were used to explore which one gives the best results. Fortunately, the oxidation proceeded reasonably well with all the quinones. All yields are shown in Scheme 2 and correlated with the one-electron reduction potential of the corresponding quinone.

Although parameters such as solubility or chemical instability of quinones are important to explain these results, the reduction potential of the quinone is the most important factor. It is wellknown that quinone redox cycling is involved in a delicate equilibrium: if quinone is a very good oxidant, the first step (generation of semiquinone) will be favoured, but the second one (regeneration of quinone) will not, and vice versa. ${ }^{8,10}$ Menadione seems to fulfil perfectly the Goldilocks principle, carrying out oxidation with air and leading to the best yield. ${ }^{14}$ Moreover, menadione is inexpensive, stable and displays low toxicity.

Encouraged by these results, a set of experiments were performed to optimize the reaction conditions (Table 1). Decreasing the amount of ascorbate leads to lower yields (entries 2 and 3), which supports that hydrogen peroxide generation is enhanced

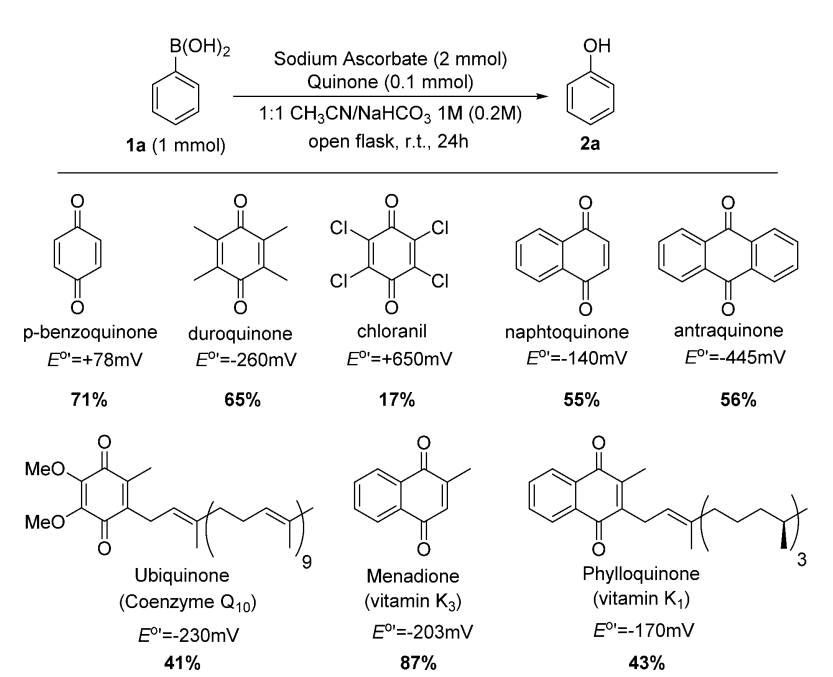

Scheme 2 ipso-Hydroxylation of phenylboronic acid with ascorbate and different quinones. Reduction potential values were taken from ref. 8 and from ref. 10 (measured in aqueous buffers around $\mathrm{pH}=7$ ).
Table 1 Optimization of the reaction conditions

\begin{tabular}{|c|c|c|c|c|c|}
\hline & $1 a$ & $\begin{array}{c}2 \begin{array}{c}\text { Sodium Ascorbate } \\
\text { Menadione }\end{array} \\
1 \mathrm{M} \text { bicarbonate buffer/ } \\
\text { organic solvent } \\
\text { open flask, r. t., } 24 \mathrm{~h}\end{array}$ & $2 a$ & & \\
\hline Entry & $\begin{array}{l}\text { Sodium ascorbate } \\
(\mathrm{mmol})\end{array}$ & $\begin{array}{l}\text { Menadione } \\
(\mathrm{mmol})\end{array}$ & $\mathrm{pH}^{a}$ & $\begin{array}{l}\text { Organic } \\
\text { solvent }^{b}\end{array}$ & $\begin{array}{l}\text { Yield }^{c} \\
(\%)\end{array}$ \\
\hline 1 & 2 & 0.1 & 8.5 & $\mathrm{CH}_{3} \mathrm{CN}$ & 87 \\
\hline 2 & 1 & 0.1 & 8.5 & $\mathrm{CH}_{3} \mathrm{CN}$ & 65 \\
\hline 3 & 0.5 & 0.1 & 8.5 & $\mathrm{CH}_{3} \mathrm{CN}$ & 45 \\
\hline 4 & 2 & 0.05 & 8.5 & $\mathrm{CH}_{3} \mathrm{CN}$ & 54 \\
\hline 5 & 2 & 0.2 & 8.5 & $\mathrm{CH}_{3} \mathrm{CN}$ & 49 \\
\hline 6 & 2 & 0.1 & 8 & $\mathrm{CH}_{3} \mathrm{CN}$ & 83 \\
\hline 7 & 2 & 0.1 & 9 & $\mathrm{CH}_{3} \mathrm{CN}$ & 85 \\
\hline 8 & 2 & 0.1 & 9.5 & $\mathrm{CH}_{3} \mathrm{CN}$ & 85 \\
\hline 9 & 2 & 0.1 & 10 & $\mathrm{CH}_{3} \mathrm{CN}$ & 78 \\
\hline 10 & 2 & 0.1 & 8.5 & EtOH & 89 \\
\hline 11 & 2 & 0.1 & 8.5 & $t$-BuOH & 83 \\
\hline 12 & 2 & 0.1 & 8.5 & AcOEt & 79 \\
\hline 13 & 2 & 0.1 & 8.5 & - & 88 \\
\hline
\end{tabular}

${ }^{a}$ Achieved by bicarbonate/carbonate buffer. ${ }^{b}$ Reaction solvent is a $1: 1$ mixture of bicarbonate buffer solution and the organic solvent $0.2 \mathrm{M}$. ${ }^{c}$ Isolated yield.

by reduction of superoxide with another molecule of ascorbate (Scheme 1b). ${ }^{15}$ Lower yield was also obtained when the amount of menadione was modified (entries 4 and 5). The optimum $\mathrm{pH}$ range is $8-9.5$, particularly $\mathrm{pH}=8.5$ (entries 6-9). Finally, the solvent does not play a key role, even when it has been reported that acetonitrile can activate $\mathrm{H}_{2} \mathrm{O}_{2}$ (entries 10-13). ${ }^{16}$ It is worth mentioning that reaction with no organic co-solvent (entry 13) gave a good yield of phenol but led to lower yields in the oxidation of more lipophilic boronic acids, due to solubility problems. Thus, ethanol was chosen as organic co-solvent, not only because of the slightly higher yield but also because of its sustainability and low toxicity. ${ }^{17}$

Next, a series of control experiments were set in order to prove that all of the reagents employed are essential for the process. Under the optimized reaction conditions but in the absence of any one of the reagents, no conversion was observed (Table 2).

These control experiments also preclude any influence of adventitious metal traces. It is important to highlight that the bicarbonate requirement (entry 5) is not related to the $\mathrm{pH}$ value. Indeed the oxidation was unsuccessful when using $1 \mathrm{M}$ solution of $\mathrm{K}_{2} \mathrm{HPO}_{4}$ instead of bicarbonate, even though both salts provide comparable ionic strength and $\mathrm{pH}$. The role of a bicarbonate anion is to activate the peroxide generated, increasing the oxidative power of hydrogen peroxide ${ }^{18}$ which by itself is a relatively poor oxidizing agent. The optimum $\mathrm{pH}$ for the reaction $(\mathrm{pH}=8.5)$ supports the hypothesis of the bicarbonate-activated peroxide, which is experimentally proved below.

Once the optimal conditions were found, the scope of this procedure was evaluated. Different types of boronic acids were successfully oxidized with air by this methodology in good yield (Scheme 3). The nature of the substituents seems to have little effect on the outcome of the reaction. Only sterically crowded 2,6-dimethylphenylboronic acid led to moderate yields of phenol 2c. Additionally, arylboronic esters, potassium trifluoroborate salts $\left(\mathrm{Ar}_{-} \mathrm{BF}_{3} \mathrm{~K}\right)$, and alkyl boronic acids can also be oxidized using this methodology (Scheme 4). ${ }^{19}$ 
Table 2 Control experiments under optimized conditions

\begin{tabular}{|c|c|c|c|c|c|}
\hline Entry & Sodium ascorbate & Menadione & Air & $\mathrm{NaHCO}_{3}$ & Yield (\%) \\
\hline 1 & + & + & + & + & 89 \\
\hline 2 & - & + & + & + & n.r. ${ }^{a}$ \\
\hline 3 & + & - & + & + & Trace \\
\hline 4 & + & + & - & + & n.r. \\
\hline 5 & + & + & + & $-^{b}$ & Trace \\
\hline
\end{tabular}

${ }^{a}$ n.r. = no reaction. ${ }^{b}$ Experiment performed using either pure water or $\mathrm{K}_{2} \mathrm{HPO}_{4}(1 \mathrm{M})$.

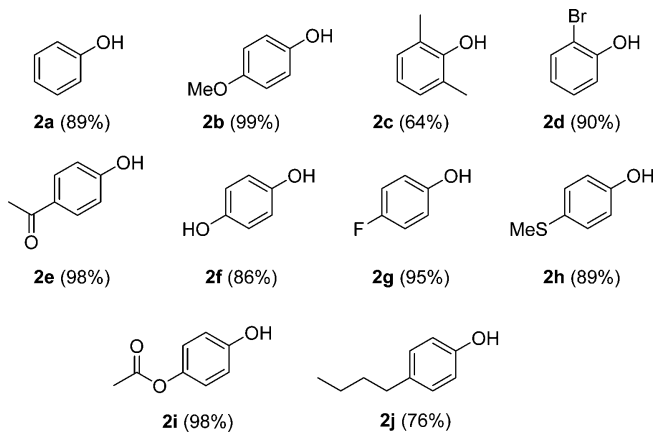

Scheme 3 Scope of ipso-hydroxylation of arylboronic acids. Oxidation carried out under optimized conditions for $24 \mathrm{~h}$.

A few other reactions that reportedly occur with $\mathrm{H}_{2} \mathrm{O}_{2}$ in the absence of metals were tested using this procedure. ${ }^{20}$ As it can be seen in Table 3, ascorbate driven menadione redox-cycling is able to epoxidize cinnamaldehyde with air in similar yields as those reported under analogous conditions with hydrogen peroxide (entry 1). ${ }^{21}$ Noteworthily, epoxidation is only successful when a catalytic amount of pyrrolidine is present, in order to favour the nucleophilic addition of the peroxide. ${ }^{22}$ Curiously, increasing the amount of ascorbate and menadione drives to over-oxidation of cinnamaldehyde yielding benzaldehyde in good yield (entry 2). ${ }^{23}$ Dakin oxidation was only achieved in poor yields, probably due to the lack of heating, and the mild basic conditions (entry 3). Oxidative decarboxylation of phenyl glyoxylic acid was successful (entry 4). And finally, concomitant ipso-hydroxylation and oxidative hydrolysis of nitrile 10 were also achieved (entry 5). Unfortunately, oxidation of sulfides or tertiary amines was unsuccessful under these conditions.

While a precise reaction mechanism awaits further study, a few mechanistic experiments support the catalytic cycle depicted
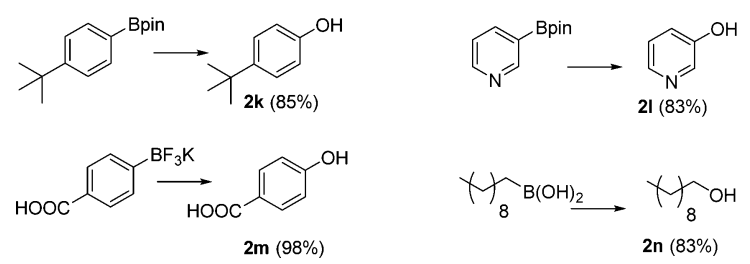

Scheme 4 ipso-Hydroxylation of arylboronic esters, potassium trifluoroborate salts and alkyl boronic acids, using the optimized conditions for $24 \mathrm{~h}$.
Table 3 Miscellaneous oxidation ${ }^{a}$

Entry Yield (\%)

${ }^{a}$ Reaction conditions (unless otherwise stated): substrate $(1 \mathrm{mmol})$, sodium ascorbate $(2 \mathrm{mmol})$, menadione $(0.1 \mathrm{mmol})$, ethanol/sodium bicarbonate $1 \mathrm{M}(1: 1), 0.2 \mathrm{M}$, stirring in air at room temperature, protected from light. ${ }^{b}$ Pyrrolidine $\left(20 \mathrm{~mol} \%\right.$ ) was added. ${ }^{c} 4 \mathrm{mmol}$ of ascorbate and $0.4 \mathrm{mmol}$ of menadione were used. ${ }^{d}$ Yield of $11: 50 \%$, yield of $12: 44 \%$.

in Scheme 1b. When the oxidation of phenylboronic acid 1a is carried out under an ${ }^{18} \mathrm{O}_{2}$ atmosphere, incorporation of such a heavier isotope of oxygen in the final compound is detected (Scheme 5). This fact proves that this methodology indeed activates the atmospheric oxygen and incorporates it into the final products. The hypothesis of hydrogen peroxide production from the oxygen of air was confirmed by detection of peroxymonocarbonate $\left(\mathrm{HCO}_{4}{ }^{-}\right)$by ${ }^{13} \mathrm{C}$ NMR (Fig. S2, ESI $\left.¥\right)$ : indeed such an anion is generated by reaction between $\mathrm{H}_{2} \mathrm{O}_{2}$ and bicarbonate, and therefore the presence of $\left(\mathrm{HCO}_{4}{ }^{-}\right)$in the reaction media necessarily implies that $\mathrm{H}_{2} \mathrm{O}_{2}$ has to be present. ${ }^{24}$ Additionally, the bicarbonate activated peroxide mechanism is also confirmed by the formation of peroxymonocarbonate, which is a stronger oxidant than hydrogen peroxide.

In summary, a novel and green method for oxidation with air is described herein. This procedure requires no transition metals but combines just two vitamins (ascorbate and menadione) at room temperature and atmospheric pressure. Hydrogen peroxide generated in situ by this method has been proven to act efficiently as an oxidant of arylboronic acids and a few other organic moieties. These results can find several applications in many fields besides synthesis, such as water decontamination, ${ }^{25}$ cosmetics, ${ }^{26}$ or even powering nanomotors. ${ }^{27}$ Further studies on combining this methodology with sustainable transition metals and chiral ligands are underway in our laboratory.

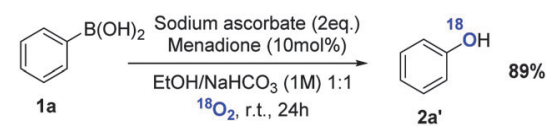

Scheme $5{ }^{18} \mathrm{O}$ labelling experiment. Determined by $\mathrm{E}$ I mass analysis. 
This research was supported by the European Commission (IMBRAIN project, FP7-REGPOT-2012-CT2012-31637-IMBRAIN), and the Spanish MECD CEI10/00018 and MINECO, co-financed by the European Regional Development Fund (ERDF), CTQ201128417-C02-01, and CTQ2011-22653. G.S.-D. thanks EU Social Fund (FSE) and ACIISI for a pre-doctoral fellowship.

\section{Notes and references}

1 (a) Modern Oxidation Methods, ed. J. E. Bäckvall, VCH-Wiley, Weinheim, 2004; (b) R. A. Sheldon, I. W. C. E. Arends, G.-J. Ten Brink and A. Dijksman, Acc. Chem. Res., 2002, 35, 774-781; (c) R. Noyori, M. Aoki and K. Sato, Chem. Commun., 2003, 1977-1983.

2 (a) J. Piera and J.-E. Bäckvall, Angew. Chem., Int. Ed., 2008, 47, 3506-3523, and references therein; (b) A. Berkessel, Adv. Inorg. Chem., 2006, 58, 1-28.

3 (a) B. F. Minaev, Int. J. Quantum Chem., 1980, 17, 367-374; (b) A. L. Buchchenko and V. L. Berdinsky, J. Phys. Chem., 1996, 100, 18292-18299.

4 Paramagnetic metals can use the exchange interaction between the unpaired spin of the metal and the oxygen species for an effective intersystem crossing, which allows the triplet to singlet spin flip. See: R. Prabhakar, P. E. M. Siegbahn, B. F. Minaev and H. Ågren, J. Phys. Chem. B, 2004, 108, 13882-13892.

5 P. Anastas and N. Eghbali, Chem. Soc. Rev., 2010, 39, 301-312.

6 (a) H. Kawai, S. Okusu, Z. Yuan, E. Tokunaga, A. Yamano, M. Shiro and N. Shibata, Angew. Chem., Int. Ed., 2013, 52, 2221-2225; (b) Y. Imada, H. Iida, S. Ono and S.-I. Murahashi, J. Am. Chem. Soc., 2003, 125, 2868-2869; (c) F. Hollmann, A. Taglieber, F. Schulz and M. T. Reetz, Angew. Chem., Int. Ed., 2007, 46, 2903-2906; (d) S. Chen and F. W. Foss Jr., Org. Lett., 2012, 14, 5150-5153; (e) R. Liu, X. Liang, C. Dong and X. Hu, J. Am. Chem. Soc., 2004, 126, 4112-4113; $(f)$ R. Mu, Z. Liu, Z. Yang, Z. Liu, L. Wu and Z.-L. Liu, Adv. Synth. Catal., 2005, 347, 1333-1336.

7 Industrial production of $\mathrm{H}_{2} \mathrm{O}_{2}$ relies almost exclusively on the anthraquinone oxidation method, which is catalyzed by transition metals. See: J. M. Campos-Martin, G. Blanco-Brieva and J. L. G. Fierro, Angew. Chem., Int. Ed., 2006, 45, 6962-6984.

8 Y. Song and G. Buettner, Free Radical Biol. Med., 2010, 49, 919-962.

9 Usually ascorbate has only been used to reduce some metals, mainly $\mathrm{Cu}(\mathrm{II})$ to $\mathrm{Cu}(\mathrm{I})$, like in the CuCAAC "click" reaction. For other uses in synthesis, see: $(a)$ F. P. Crisóstomo, T. Martín and R. Carrillo, Angew. Chem., Int. Ed., 2014, 53, 2181-2185; (b) D. L. Browne, I. R. Baxendale and S. V. Ley, Tetrahedron, 2011, 67, 10296-10303.

10 V. Roginsky, T. Barsukova and H. B. Stegmann, Chem.-Biol. Interact., 1999, 121, 177-197.

11 (a) J. Verrax, R. Beck, N. Dejeans, C. Glorieux, B. Sid, R. C. Pedrosa, J. Benites, D. Vásquez, J. A. Valderrama and P. B. Calderon, Anti-Cancer Agents Med. Chem., 2011, 11, 213-221; (b) R. Pethig, P. R. C. Gascoyne,
J. A. Mclaughlin and A. Szent-Gyorgyi, Proc. Natl. Acad. Sci. U. S. A., 1983, 80, 129-132; (c) J. Verrax, J. Cadrobbi, M. Delvaux, J. M. Jamison, J. Gilloteaux, J. L. Summers, H. S. Taper and P. B. Calderon, Eur. J. Med. Chem., 2003, 38, 451-457; (d) R. Beck, J. Verrax, N. Dejeans, H. Taper and P. B. Calderon, Internet J. Toxicol., 2009, 28, 33-42.

12 Q. Chen, M. G. Espey, A. Y. Sun, J.-H. Lee, M. C. Krishna, E. Shacter, P. L. Choyke, C. Pooput, K. L. Kirk, G. R. Buettner and M. Levine, Proc. Natl. Acad. Sci. U. S. A., 2007, 104, 8749-8754.

13 (a) Z. He and T. F. Jamison, Angew. Chem., Int. Ed., 2014, 53, 3353-3357; (b) Y.-Q. Zou, J.-R. Chen, X.-P. Liu, L.-Q. Lu, R. L. Davis, K. A. Jørgensen and W.-J. Xiao, Angew. Chem., Int. Ed., 2012, 51, 784-788; (c) S. P. Pitre, C. D. McTiernan, H. Ismaili and J. C. Scaiano, J. Am. Chem. Soc., 2013, 135, 13286-13289; (d) C. Zhu, R. Wang and J. R. Falck, Org. Lett., 2012, 14, 3494-3497; (e) Y. Zhong, L. Yuan, Z. Huang, W. Gu, Y. Shao and W. Han, RSC Adv., 2014, 4, 33164-33167; $(f)$ H. Jiang, L. Lykke, S. U. Pedersen, W.-J. Xiao and K. A. Jørgensen, Chem. Commun., 2012, 48, 7203-7205; $(g)$ W. Ding, J.-R. Chen, Y.-Q. Zou, S.-W. Duan, L.-Q. Lu and W.-J. Xiao, Org. Chem. Front., 2014, 1, 151-154; (h) P. Kaewmati, E. Somsook, R. N. Dhital and H. Sakurai, Tetrahedron Lett., 2012, 53, 6104-6106. 14 J. N. Bull, C. W. West and J. R. Verlet, Chem. Sci., 2015, 6, 1578-1589. 15 E. J. Nanni Jr., M. D. Stallings and D. T. Sawyer, J. Am. Chem. Soc., 1980, 102, 4481-4485.

16 G. B. Payne, P. H. Deming and P. H. Williams, J. Org. Chem., 1961, 26, 659-663.

17 Reactions in pure $\mathrm{O}_{2}$ led to similar yields. We chose open flask reactions because they are much more sustainable and affordable.

18 (a) H. Yao and D. E. Richardson, J. Am. Chem. Soc., 2000, 122, 3220-3221; (b) D. E. Richardson, H. Yao, K. M. Frank and D. A. Bennett, J. Am. Chem. Soc., 2000, 122, 1729-1739; (c) B. Balagam and D. E. Richardson, Inorg. Chem., 2008, 47, 1173-1178.

19 Initial attempts to oxidize alkenyl boronic acids were unsuccessful.

20 We have chosen known transition metal free reactions in order to assure that metals have no influence on the generation of hydrogen peroxide or other reactive oxygen species.

21 W. Zhuang, M. Marigo and K. A. Jørgensen, Org. Biomol. Chem., 2005, 3, 3883-3885.

22 Promising results with chiral prolinol derivatives will be reported elsewhere.

23 P. Wright and J. Abbot, Int. J. Chem. Kinet., 1993, 25, 901-911.

24 E. V. Bakhmutova-Albert, H. Yao, D. E. Denevan and D. E. Richardson, Inorg. Chem., 2010, 49, 11287-11296.

25 (a) W. C. Ellis, C. T. Tran, R. Roy, M. Rusten, A. Fischer, A. D. Ryabov, B. Blumberg and T. J. Collins, J. Am. Chem. Soc., 2010, 132, 9774-9781; (b) B. M. Smith, Chem. Soc. Rev., 2008, 37, 470-478.

26 J. Marsh, R. M. Dahlgren, C. Clarke, J. Stonehouse and C. Nunn, J. Cosmet. Sci., 2009, 60, 205-215.

27 S. Sánchez, L. Soler and J. Katuri, Angew. Chem., Int. Ed., 2015, 54, 1414-1444, and references therein. 